\title{
Estimation of Coefficients of Radar Reflectivity Factor and Rainfall Rate using Blue Nile Weather Radar Data, of Ethiopia
}

\author{
Nigus Yibeltal Tesfa \\ Bahir Dar Institute of Technology \\ Bahir Dar University, Ethiopia
}

\begin{abstract}
Rain gauge measurement represents only point rainfall and considered as the "ground truth" for rainfall rate, but it is associated with different errors and exposed to outliers. On the other hand radar does not directly measure rainfall rates, but it estimates rainfall rate, $R(\mathrm{~mm} / \mathrm{h})$ by an empirical relationship with the radar reflectivity factor, $Z\left(\mathrm{~mm}^{6} / \mathrm{m}^{3}\right)$. Reflectivity is converted into a rainfall rate by the $Z-R$ relationship using the formula: $Z=a R^{b}$ and we determine both of the coefficients (with $95 \%$ confidence bounds) $\mathrm{a}=27(23.57,30.43) \& \quad \mathrm{~b}=0.1592 \quad(0.1036,0.2147), \mathrm{a}=19.83(14.57,25.1) \quad \& \quad \mathrm{~b}=0.2875(0.1884,0.3865)$ and $\mathrm{a}=20.93(18.08,23.78) \& \quad \mathrm{~b}=0.2684(0.214,0.3228)$ For Bahir Dar station- I, Bahir Dar station-II and the overall station respectively.
\end{abstract}

Key Terms: Reflectivity, Z-R relationship, Doppler radars.

\section{INTRODUCTION}

Weather radar is basically a radio transmitter that sends a pulse of energy that interacts with the precipitation in the atmosphere. Weather radar does not continuously transmit energy. It sends a pulse of energy for a short period of time, and then listens for that energy to return to the antenna. The returned energy to the radar is processed by the radar software into three types of data: reflectivity; Doppler velocity; and spectrum width.

Reflectivity is a measure of the energy returned by the atmosphere to the radar. It is the measure of the strength of the reflected energy. The stronger reflectivity value means the stronger intensity of the precipitation detected by the radar.

$>$ Doppler radars have the ability to detect the change in frequency between emitted and reflected signals. This shift in frequency is due to the motion of the reflecting medium. This change is converted to a Doppler velocity that measures the movement along the beam. It does not measure motion across the beam.

Spectrum width is a measure of the uncertainty in the velocity measurements

One of the important parameters measured by weather radar systems is the reflectivity of the precipitation targets in the volume of atmosphere being observed. A key issue in radar-based rainfall estimation is to identify the relationships between reflectivity ( $Z$ ) and rain intensity $(R)$. In ideal conditions, reflectivity is closely related to backscattered radar energy from raindrops in the atmosphere. Both $Z$ and $R$ are defined as different moments of the drop size distribution in a sampled volume (Sauvageot 1992). However, these definitions alone do not imply a straightforward functional relationship between the two variables. The past studies indicate that on average $Z$ and $R$ can be related by a power law:

$$
\mathbf{Z}=\mathbf{a R}^{\mathbf{b}}
$$




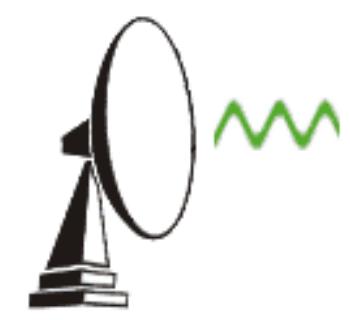

Figure 1: Bahir Dar weather radar

\section{SOURCES OF DATA}

The data used for this study were collected from one source of weather radar data and a number of surface station gauge data deployed in Amhara region and the weather radar station also operated by Ethiopian National Meteorology Agency is located at Shawra, The weather radar covers the regions of Amhara, Tigray, Benishangul, some parts of Oromia, most north western parts and central parts of Ethiopia. Location of stations in Amhara region and the specification of Bahir Dar weather radar are presented in the following table \& figure.

Table 1: The Specification of Bahir Dar Weather Rada

\begin{tabular}{|l|l|}
\hline Parameters & Values \\
\hline Band & C \\
\hline Transmitter & Magnetron \\
\hline Frequency & $5.5-5.7 \mathrm{GHZ}$ \\
\hline Peak Power & $250 \mathrm{KW}$ \\
\hline Average Power & $300 \mathrm{~W}$ \\
\hline Duty Cycle & $0.12 \%$ \\
\hline Pulse Width & $0.5-2.0$ mili second \\
\hline PRF & $600 \mathrm{HZ}$ \\
\hline Antenna Diameter & $4.5 \mathrm{~m}$ \\
\hline Gain & $45 \mathrm{Db}$ \\
\hline Beam Width & $<1 \mathrm{degree}$ \\
\hline Polarization & Dual (Vertical \& Horizontal) \\
\hline Maximum Scan Rate & $40 \mathrm{deg} /$ second \\
\hline
\end{tabular}

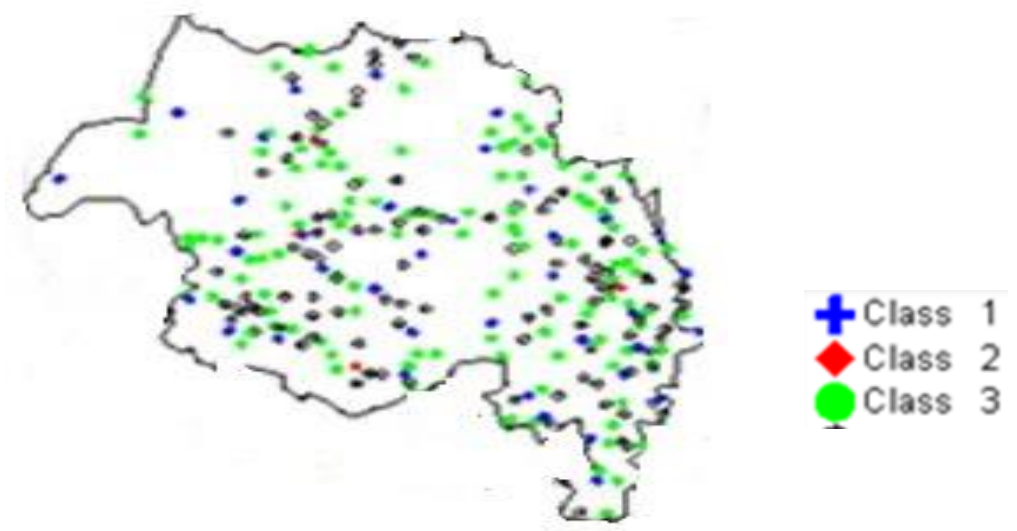

Figure 2: The Distribution of the Surface Gauge stations in Amhara Region 


\section{OBJECTIVE}

The objective of this study is to

$>$ Estimate Z-R relationship parameters for the area

$>$ Compare precipitation from the two ground-gauge instruments with the radar reflectivity data

\section{METHODOLOGY}

Rain gauge measurement represents only point rainfall and considered as the "ground truth" for rainfall rate, but it is associated with different errors and exposed to outliers. On the other hand radar does not directly measure rainfall rates, but it estimates rainfall rate, $R$ $(\mathrm{mm} / \mathrm{h})$ by an empirical relationship with the radar reflectivity factor, $\mathrm{Z}$ (mm6/m3). According to Peter G. (2001), Rainfall rates are proportional to the volume of the raindrops, but reflectivity is proportional to sixth-power of the drop diameter. Therefore, a raindrop size distribution must be assumed to convert from reflectivity to rainfall rate. Reflectivity is converted into a rainfall rate by the ZRrelationship using the formula:

Where: $\quad Z$ is reflectivity $\left(\mathrm{mm}^{6} \mathrm{~m}^{-3}\right)$,

$$
\mathrm{Z}=\mathrm{aR}^{\mathrm{b}}
$$

$R$ is rainfall intensity $\left(\mathrm{mm} \mathrm{h}^{-1}\right)$, and $a \& b$ are empirical parameters.

\section{RELATIONSHIP BETWEEN RADAR REFLECTIVITY \& RAINFALL RATE}

The relationship between measured $\mathrm{Z}$ and $\mathrm{R}$ is complex and the estimation procedure is subject to several independent sources of error (Austin1987; Jossand Lee 1995). The geometry of the radar beam leads to the radar's measurement of reflectivity to be made 100s to 1000s of $\mathrm{m}$ above the surface. Biases in the estimate of the near-surface reflectivity of rain can result from the following:

$>$ Vertical variation of reflectivity in the storm between the measurement several $\mathrm{km}$ above the surface and the surface;

$>$ errors in radar calibration;

$>$ non-meteorological echoes such a ground clutter and anomalous propagation;

$>$ attenuation; and

$>$ The presence of non-rain hydrometeors such as graupel, hail, and melting snow. These potential sources of bias can be removed or minimized by established methods. For the purposes of this paper, we will assume that such procedures are utilized. We will focus on the relatively smaller magnitude biases in the mapping of $Z$ to $R$ (Jossand Lee 1995) associated with variations in the raindrop size distribution.

\section{PARAMETER ESTIMATION METHOD}

A Z-R relationship to estimation precipitation rate at ground level is assumed as extrapolated from a combination of radar and rain gauge observations (Dutta et al., 2012).

Table 2: Reflectivity and surface gauge measurement of rainfall rate data for the two stations

\begin{tabular}{|l|l|l|l|l|}
\hline \multirow{2}{*}{ Date } & \multicolumn{2}{|c|}{ Bahir Dar Station I } & \multicolumn{2}{l|}{ Bahir Dar Station II } \\
\cline { 2 - 5 } & Z(dBZ) & Gauge $(\mathrm{mm} /$ day $)$ & Z(dBZ) & Gauge (mm/day) \\
\hline $22 / 06 / 2016$ & 40 & 13 & 43 & 14.5 \\
\hline $23 / 06 / 2016$ & 41 & 12 & 31 & 4.2 \\
\hline $24 / 06 / 2016$ & 38 & 8.7 & 26.9 & 0 \\
\hline $25 / 06 / 2016$ & 37 & 7 & 46.6 & 16.3 \\
\hline $26 / 06 / 2016$ & 38 & 8.7 & 37 & 12.9 \\
\hline $27 / 06 / 2016$ & 37 & 7.5 & 50.11 & 22.6 \\
\hline $28 / 06 / 2016$ & 40 & 12 & 45 & 18.7 \\
\hline
\end{tabular}



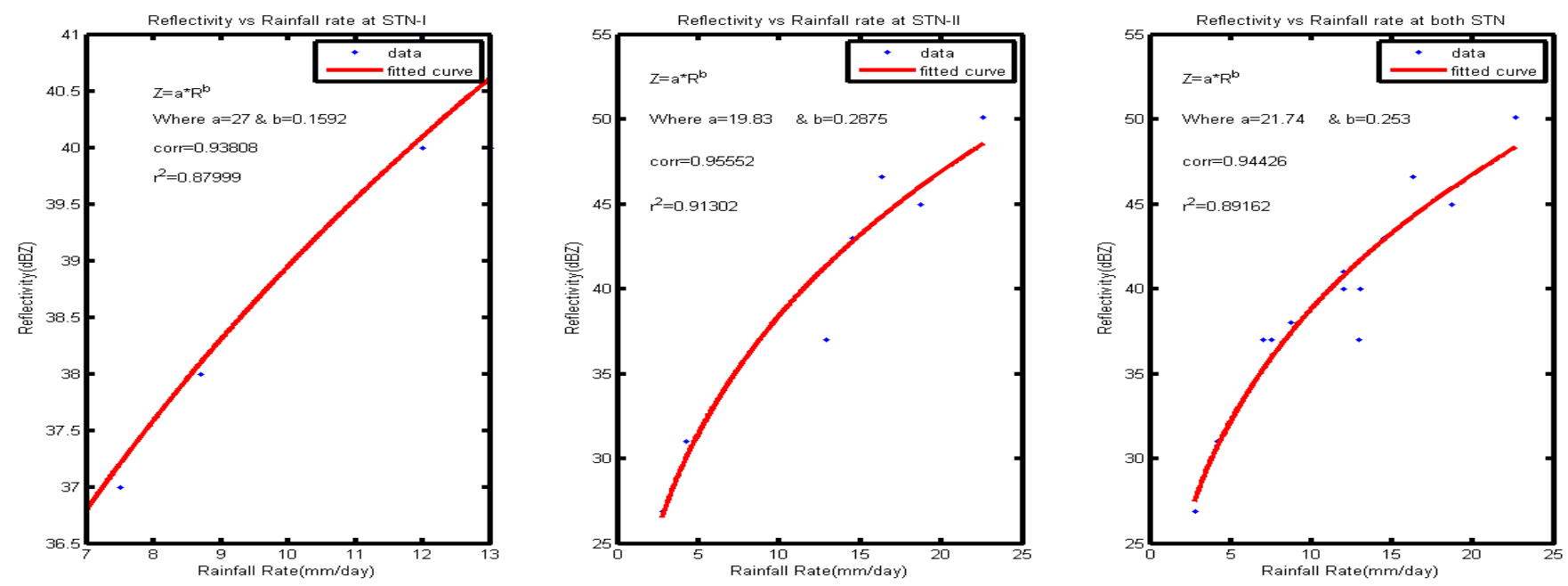

Figure 3: The correlation between reflectivity and measured rainfall rate
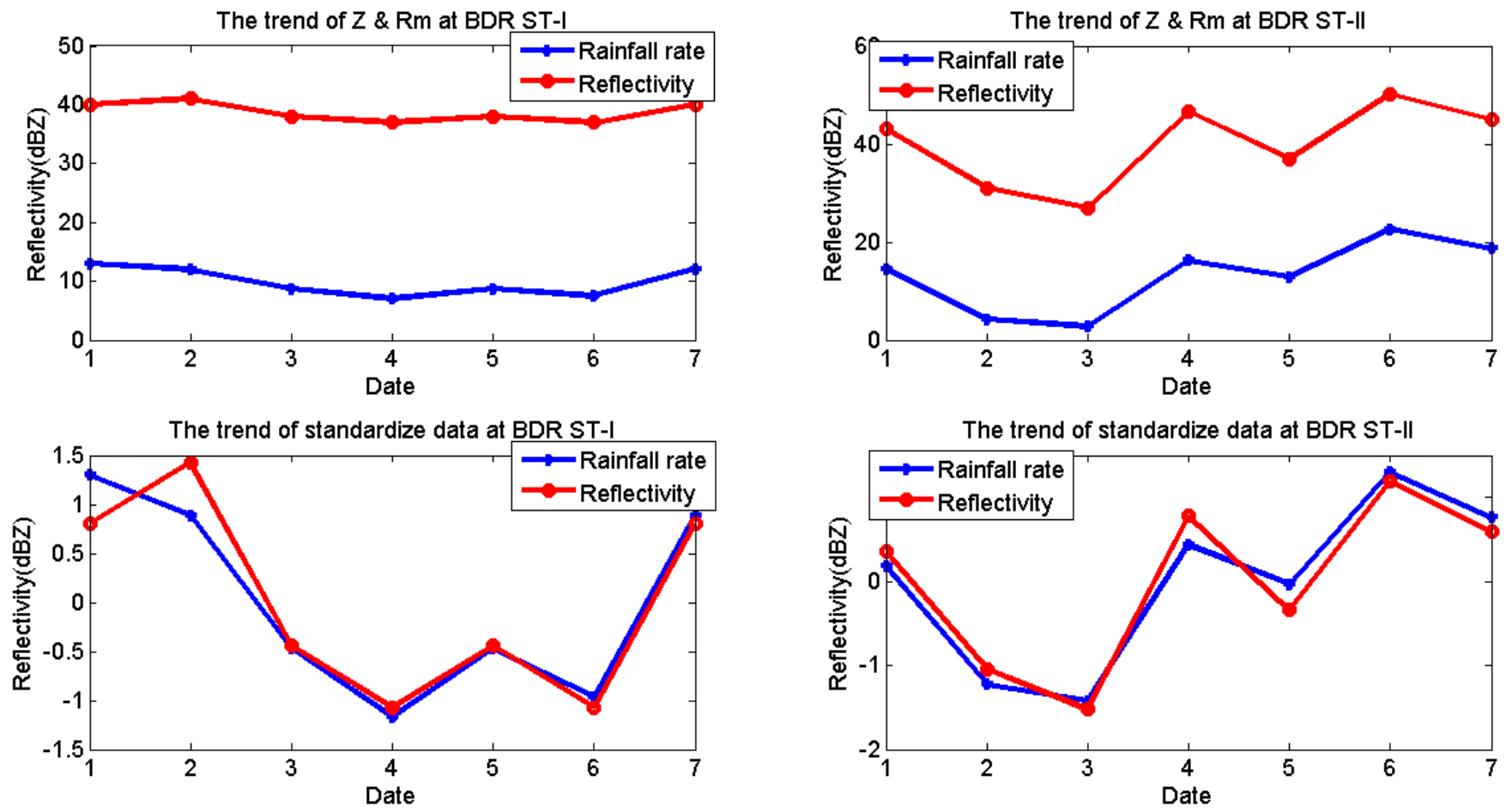

Figure 4: The trend of reflectivity and measured rainfall rate

From figure 4 the data of radar reflectivity and measured rainfall rate have the similar trend. Now after interpolating the outliers of the data we will transform both $\mathrm{Z}$ and $\mathrm{R}$ in to $\ln \mathrm{z}$ and $\ln \mathrm{R}$ to model the relationship between reflectivity and rainfall rate through regression data analysis tool. Regression Analysis helps us to make predictions of inside and outside the given data values. 
International Journal of Engineering Research And Advanced Technology, Vol.6 (12), December-2020

Table 3: The transformed data to natural log

\begin{tabular}{|c|c|c|c|c|c|c|c|c|}
\hline \multirow[b]{3}{*}{ Date } & \multicolumn{4}{|c|}{ Z-R Data } & \multicolumn{4}{|c|}{ ln Z -ln R Transformed Data } \\
\hline & \multicolumn{2}{|c|}{ Bahir Dar Station I } & \multicolumn{2}{|c|}{ Bahir Dar Station II } & \multicolumn{2}{|c|}{ Bahir Dar Station I } & \multicolumn{2}{|c|}{ Bahir Dar Station II } \\
\hline & $\mathrm{Z}(\mathrm{dBZ})$ & $\begin{array}{l}\text { Gauge } \\
\mathrm{R}(\mathrm{mm} / \text { day })\end{array}$ & $\mathrm{Z}(\mathrm{dBZ})$ & $\begin{array}{l}\text { Gauge } \\
\mathrm{R}(\mathrm{mm} / \text { day })\end{array}$ & $\begin{array}{l}\ln \\
\mathrm{Z}(\mathrm{dBZ})\end{array}$ & $\begin{array}{l}\text { Gauge } \\
\mathrm{R}(\mathrm{mm} / \text { day })\end{array}$ & $\mathrm{Z}(\mathrm{dBZ})$ & $\begin{array}{l}\text { Gauge } \\
\mathrm{R}(\mathrm{mm} / \text { day })\end{array}$ \\
\hline $22 / 06 / 2016$ & 40 & 13 & 43 & 14.5 & 3.69 & 2.56 & 3.76 & 2.67 \\
\hline $23 / 06 / 2016$ & 41 & 12 & 31 & 4.2 & 3.71 & 2.48 & 3.43 & 1.44 \\
\hline $24 / 06 / 2016$ & 38 & 8.7 & 26.9 & 2.77 & 3.64 & 2.16 & 3.29 & 1.02 \\
\hline $25 / 06 / 2016$ & 37 & 7 & 46.6 & 16.3 & 3.61 & 1.95 & 3.84 & 2.79 \\
\hline $26 / 06 / 2016$ & 38 & 8.7 & 37 & 12.9 & 3.64 & 2.16 & 3.61 & 2.56 \\
\hline $27 / 06 / 2016$ & 37 & 7.5 & 50.11 & 22.6 & 3.61 & 2.01 & 3.91 & 3.12 \\
\hline $28 / 06 / 2016$ & 40 & 12 & 45 & 18.7 & 3.69 & 2.48 & 3.81 & 2.93 \\
\hline
\end{tabular}

Table 4: Log-log regression model for Each Stations

SUMMARY OUTPUT FOR BAHIR DAR STATION-I

\begin{tabular}{|c|c|c|c|c|c|c|}
\hline \multicolumn{2}{|l|}{ Regression Statistics } & & & & & \\
\hline Multiple R & 0.960 & & & & & \\
\hline R Square & 0.921 & & & & & \\
\hline Adjusted $\quad$ R & & & & & & \\
\hline Square & 0.905 & & & & & \\
\hline Standard Error & 0.013 & & & & & \\
\hline Observations & 7.000 & & & & & \\
\hline \multicolumn{7}{|l|}{ ANOVA } \\
\hline & $d f$ & $S S$ & $M S$ & $F$ & Significance $F$ & \\
\hline Regression & 1.000 & 0.009 & 0.009 & $\mathbf{5 8 . 4 7 9}$ & 0.001 & \\
\hline Residual & 5.000 & 0.001 & 0.000 & & & \\
\hline Total & 6.000 & 0.010 & & & & \\
\hline & Coefficients & Standard Error & $t$ Stat & P-value & Lower 95\% & Upper $95 \%$ \\
\hline Intercept & 3.296 & 0.047 & 69.695 & 0.000 & 3.174 & 3.417 \\
\hline X Variable 1 & 0.159 & 0.021 & 7.647 & 0.001 & 0.106 & 0.213 \\
\hline \multicolumn{7}{|c|}{ SUMMARY OUTPUT BAHIR DAR STATION-II } \\
\hline \multicolumn{7}{|l|}{ Regression Statistics } \\
\hline Multiple R & \multicolumn{2}{|l|}{0.97} & & & & \\
\hline R Square & \multicolumn{2}{|l|}{0.94} & & & & \\
\hline Adjusted R Square & \multicolumn{2}{|l|}{0.93} & & & & \\
\hline Standard Error & \multicolumn{2}{|l|}{0.06} & & & & \\
\hline Observations & \multicolumn{2}{|l|}{$\mathbf{7 . 0 0}$} & & & & \\
\hline \multicolumn{7}{|l|}{ ANOVA } \\
\hline & \multicolumn{2}{|l|}{$D f$} & $M S$ & $\boldsymbol{F}$ & Significance $F$ & \\
\hline Regression & 1.00 & 0.30 & $\mathbf{0 . 3 0}$ & 85.38 & 0.0001 & \\
\hline Residual & 5.00 & 0.02 & 0.00 & & & \\
\hline \multirow[t]{2}{*}{ Total } & 6.00 & 0.32 & & & & \\
\hline & Coefficients & ts Standard Error & t Stat & P-value & Lower $95 \%$ & Upper 95\% \\
\hline Intercept & 3.01 & 0.07 & 40.33 & 0.00 & 2.82 & 3.20 \\
\hline X Variable 1 & 0.28 & 0.03 & 9.24 & 0.00 & 0.20 & 0.36 \\
\hline
\end{tabular}


From table 4: The correlation coefficient $r=0.96 \& 0.97$ shows that the two variables (reflectivity and measured rainfall rate) on both stations are correlated highly and positively. Similarly, the coefficient of determination $r$ square $\left(R^{2}=0.921 \& 0.94\right)$ shows that the model is a good fit and acceptable to predict the rainfall rate from the radar reflectivity data with the relationship between $\mathrm{Z}$ and $\mathrm{R}$.

For the estimation of parameters, the least square method and regression is widely used in different problems.

$$
Z=a R^{b}
$$

To get a linear relation between the two parameters taking the logarithm of the equation as follows

$$
\ln Z=\ln a+b \ln R
$$

Where $n=1,2,3, \ldots, n, n$ is the sample size and

From table 4 and equation (2); $\ln a=3.296$ and $b=0.159$

$$
\ln Z=3.296+0.159 \ln R \text {. }
$$

Applying $e$ to both sides of the equation yields

$$
\begin{aligned}
& Z=e^{3.296+0.159 \ln R} \ldots \ldots . . . \\
& Z=e^{3.296} * e^{0.159 \ln R} \\
& Z=e^{3.296 * R^{0.159}}
\end{aligned}
$$

Therefore $a=27 \& b=0.159$ for Bahir Dar surface gauge station-I and $a=19.83 \& b=0.2875$ for Bahir Dar surface gauge station - II

Table 5: Estimated parameters of Z-R relation for Bahir Dar Region on June

\begin{tabular}{|l|l|l|l|l|}
\hline \multirow{2}{*}{ Stations } & \multicolumn{2}{|c|}{$95 \%$ Confidence bounds } \\
\cline { 2 - 5 } & Coefficents & Value & Minimum & Maximum \\
\hline \multirow{3}{*}{ Bahir Dar Station I } & $\mathrm{a}$ & 27 & 23.57 & 30.43 \\
\cline { 2 - 5 } & $\mathrm{b}$ & 0.159 & 0.1036 & 0.2147 \\
\hline \multirow{3}{*}{ Bahir Dar Station II } & $\mathrm{a}$ & 19.83 & 14.57 & 25.1 \\
\cline { 2 - 5 } All in one & $\mathrm{b}$ & 0.2875 & 0.1884 & 0.3865 \\
\hline & $\mathrm{a}$ & 20.93 & 18.08 & 23.78 \\
\cline { 2 - 5 } & $\mathrm{b}$ & 0.2684 & 0.214 & 0.3228 \\
\hline
\end{tabular}

From the measured surface gauge and radar reflectivity data $\mathrm{Z}=\mathrm{aR}^{\mathrm{b}}$ by using power regression model, we determine Coefficients (with $95 \%$ confidence bounds) $\quad a=27(23.57,30.43) \& \quad b=0.1592 \quad(0.1036,0.2147), a=19.83(14.57,25.1) \&$

$\mathrm{b}=0.2875(0.1884,0.3865)$ and $\mathrm{a}=20.93(18.08,23.78) \& \quad \mathrm{~b}=0.2684(0.214,0.3228)$ for Bahir Dar station- I, Bahir Dar station-II and all in one stations respectively. Which is different from the early studies, suggested by Marshall and Palmer (1948), for the parameters of $a=250$ and $b=1.2$ for under tropical rainfall events of a power-law $Z-R$ relationship. Many subsequent studies like (Rosenfeld et al. 1993) also found that different values for the parameters $a=200$ and $b=1.6$ for tropical region. However, in our case the radar is under tropical region but the estimated parametres are not the same as that of the previous studies.

Table 6: Predicted and measured rainfall rate data for Bahir Dar Region on June

\begin{tabular}{|l|l|l|l|l|}
\hline \multirow{2}{*}{ Date } & \multicolumn{2}{|c|}{ Bahir Dar Station I } & \multicolumn{2}{l|}{ Bahir Dar Station II } \\
\cline { 2 - 5 } & $\begin{array}{l}\text { Predicted } \\
\text { R (mm/day) }\end{array}$ & $\begin{array}{l}\text { Gauge } \\
\text { R (mm/day) }\end{array}$ & $\begin{array}{l}\text { Predicted } \\
\text { R (mm/day) }\end{array}$ & $\begin{array}{l}\text { Gauge } \\
\text { R (mm/day) }\end{array}$ \\
\hline $22 / 06 / 2016$ & 11.85 & 13.00 & 14.96 & 14.50 \\
\hline $23 / 06 / 2016$ & 13.84 & 12.00 & 4.61 & 4.20 \\
\hline $24 / 06 / 2016$ & 8.58 & 8.70 & 2.77 & 2.77 \\
\hline $25 / 06 / 2016$ & 7.25 & 7.00 & 19.97 & 16.30 \\
\hline $26 / 06 / 2016$ & 8.58 & 8.70 & 8.71 & 12.90 \\
\hline $27 / 06 / 2016$ & 7.25 & 7.50 & 25.94 & 22.60 \\
\hline $28 / 06 / 2016$ & 11.85 & 12.00 & 17.62 & 18.70 \\
\hline
\end{tabular}


Table 6: shows that the predicted rainfall rate from radar reflectivity and measured gauge rainfall data by using the Z-R relationship and the values of $a$ and $b$ from regression power model for both stations at Bahir Dar city
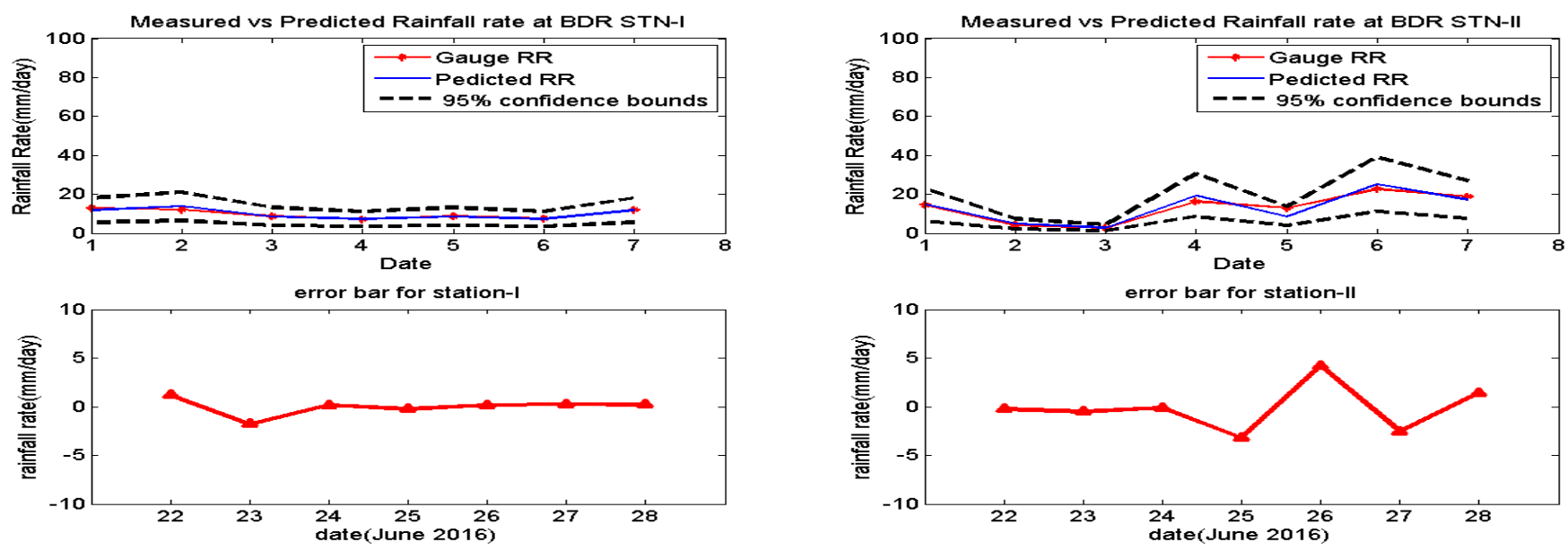

Figure 5: Predicted Rainfall rate with $95 \%$ Confidence Bounds with Error Bar

\section{CONCLUSION}

The Z-R relationships were compared by using the seven days daily data of radar reflectivity and measured gauge rainfall rates of both Bahir dar station-I and Bahir Dar Station-II on June, 2016. The coefficient of determination $r$ square $\left(\mathrm{R}^{2}=0.921 \& 0.94\right)$ shows that the model is a good fit and acceptable to predict the rainfall rate from the radar reflectivity data with the relationship between $\mathrm{Z}$ and $\mathrm{R}$. The estimated values of the rainfall rate by using the values of the parameters shows a great accuracy to predict the rainfall rate from radar reflectivity in the area. However, the parameters for the power model Z-R relationship has different values from the previous studies for tropical regions. This may be because of either a lack of reliable and consistent radar data for the region or the type and the size of rain drop diameter differences. On the other hand radar reflectivity and rainfall rates are correlated highly and positively $(+0.96$ $\&+0.97)$. The results shown in this paper highlight the importance of the use of weather radar information in order to estimate correctly the spatial rainfall rate for Bahir dar city.

\section{REFERENCE}

[1] Sauvageot, H., 1992: Radar Meteorology. Artech House, 366 pp.

[2] Marshall, J. S., and W. M. Palmer, 1948: The distribution of raindrops with size.J. Meteor., 5, 165-166. Link

[3] Rosenfeld, D., D. B. Wolff, and D. Atlas, 1993: General probability-matched relations between radar reflectivity and rain rate.J. Appl. Meteor., 32, 50-72. Link

[4] Dutta, D., Sharma, S., Kannan, B. A. M., Venketswarlu, S., Gairola, R. M., Rao, T. N., \& Viswanathan, G. (2012). Sensitivity of Z-R relations and spatial variability of error in a Doppler Weather Radar measured rain intensity. Indian Journal of Radio \& Space Physics, 41, 448-460.

[5] Peter G. (2001). Stochastic Modeling of Scientific Data. A CRC press company. New York 